\title{
Publio Clodio y la lex de collegiis: una aproximación al fenómeno asociativo a finales de la República romana
}

\author{
Publius Clodius and the lex de collegiis: an approach to the \\ associative movement at the end of the Roman Republic
}

\author{
LUIS MANUEL LÓPEZ ROMÁN*
}

\begin{abstract}
RESUMEN
En el año 58 a.C. Publio Clodio, por entones tribuno de la plebe, logró la aprobación de un significativo número de proyectos legislativos de profundo alcance social y político para el Estado romano. Entre las leyes promovidas por el tribuno se encontraba una lex de collegiis que devolvía a la legalidad a los collegia de la ciudad de Roma, abolidos pocos años antes por el Senado. Los nuevos collegia revividos o creados al amparo de esta ley constituirán un factor de gran importancia en el juego político de toda la década de los cincuenta, por su alta capacidad de presión e influencia en las asambleas y los comicios. ¿Qué eran en realidad estos collegia? ¿A qué niveles funcionaban? ¿Qué unía a sus miembros? ¿Qué influencia real ejerció Publio Clodio sobre ellos una vez lograda su reinstauración? El objetivo del presente trabajo es el análisis de estos grupos urbanos como entidades de solidaridad mutua, posiblemente más
\end{abstract}

\begin{abstract}
During the year 58 B.C. Publius Clodius, by then tribunus plebis, managed to pass a considerable number of legislative proyects with a broad social and political reach for the Roman State. Among the laws promoted by the tribune we find a lex de collegiis that restores the legal status to the collegia of Rome, abolished a few years before by the Senate. The new collegia created under this law will comprise a determining factor in political life of the fifties because of their influence in the assemblies and the comitia. ¿What were actually these collegia? ¿What were the common interest for their members? ¿Which factual influence did Publius Clodius have on collegia once the law was passed? The main point of this paper is the analysis of these urban groups as entities of mutual solidarity, probably more complex than craftsman's unions or religious brotherhoods, in order to study them from a new anthropological and historical perspective.
\end{abstract}

* Departamento de Historia Antigua. Universidad Complutense de Madrid (C/Profesor Aranguren s/n. 28040 Madrid). E-mail: pompeyo82@ hotmail.com.

Artículo basado en la comunicación leída el 20 de Mayo de 2008, en la VII edición del Encuentro de Jóvenes Investigadores de Historia Antigua de la Universidad Complutense de Madrid. 
complejos que simples sindicatos de artesanos o cofradías religiosas, para abordar desde una nueva perspectiva antropológica e histórica el estudio de las fuentes que, de forma mayoritaria, nos presentan estos colectivos como asociaciones de delincuentes, libertos e incluso esclavos.

PALABRAS CLAVE:

Clodio, collegia, Compitalia, lex Clodia de collegiis.
KEYWORDS:

Clodius, collegia, Compitalia, lex Clodia de collegiis.

\section{LOS COLLEGIA DE LA CIUDAD DE ROMA}

En los primeros días de enero del año 58 a.C., Publio Clodio, elegido tribuno de la plebe tras un complejo y controvertido proceso de transitio ad plebem, presentó a los comicios por tribus un conjunto de cuatro propuestas legislativas que perseguían una serie de profundas reformas sociales y políticas en el cuerpo de la República romana. Uno de los proyectos presentados fue la rogatio Clodia de collegiis restituendis novisque instituendis. La aprobación de esta rogatio por las tribus dejaba sin validez un senatus consultum del año 64 a.C. mediante el cual habían quedado prohibidos y disueltos todos los collegia de la ciudad de Roma. De esta forma, Clodio logró no sólo devolver la legalidad a estas asociaciones, sino crear otras nuevas, proyecto éste que ha sido tradicionalmente presentado, debido a la parcial información que nos ofrece Cicerón, como la búsqueda por parte del tribuno de una base de poder e influencia entre la plebe urbana desde la cual desarrollar su carrera política posterior mediante el recurso de la violencia.

Tratar de reconstruir qué eran exactamente los collegia antes y después de la lex Clodia resulta una tarea considerablemente problemática. Nuestra fuente literaria principal la constituyen los discursos y la correspondencia privada de Cicerón. El resto de testimonios útiles para reconstruir la realidad de los collegia son, o bien de carácter epigráfico, procedentes en su mayoría de ciudades distintas a Roma, o bien fuentes literarias tardías y alejadas de la época republicana. Cicerón, por su parte, como víctima directa de las medidas legislativas de Clodio y de la escalada de violencia que sufrió la ciudad de Roma tras su tribunado, presenta los collegia como simples asociaciones de esclavos o libertos concebidas para enturbiar el normal desarrollo de la vida política en la Urbe. La organización de las bandas callejeras al servicio de Clodio es puesta por Cicerón en relación directa con el restablecimiento de los collegia, por lo que, siempre según el orador, habría que buscar en la lex de collegiis el origen último de la violencia que dominó la ciudad en los últimos años 50 y que llegó a paralizar los procesos electorales durante varios meses.

La poderosa oratoria del Arpinate presenta a los seguidores de Clodio relacionados con los collegia como servi, esclavos que, gracias a la política del tribuno, 
Publio Clodio y la lex de collegiis: una aproximación al fenómeno asociativo...

se habrían adueñado de las calles y de las asambleas. El uso del temor ante las revueltas de esclavos como argumento retórico es una constante en los discursos de Cicerón que no puede tomarse como un reflejo de la realidad: como veremos, tanto los collegia como, por extensión, las llamadas bandas de Clodio, debieron de contar entre sus filas tanto con libertos como con individuos libres, así como también con miembros de condición servil. La relación directa y exclusiva entre los collegia y los esclavos existe únicamente en la oratoria de Cicerón, por lo que sus palabras han de tomarse con suma cautela. La intención del orador no es otra que la de utilizar el miedo de sus oyentes ante la amenaza servil al tiempo que degradaba a los individuos que pertenecían a la factio clodiana comparándolos con esclavos (Pina Polo 1991: 139).

Si bien, como veremos, la presencia de la población servil en los collegia está suficientemente documentada, resulta muy dudoso que superaran en número a los libertos o individuos libres inscritos en la mayoría de estas asociaciones. Observando por tanto las especiales características de nuestras fuentes, podemos comprender que cualquier intento de definición más o menos exacta sobre la naturaleza, composición y funciones de los collegia en Roma haya resultado fuente de controversia entre los especialistas.

Considero un punto de partida sólido el definir los collegia como asociaciones de tipo voluntario cuyos miembros compartían una serie de objetivos e intereses comunes. Los collegia completaban los aspectos de la sociabilidad del habitante de la Urbe que quedaban fuera de la esfera de las instituciones estatales y de las redes de parentesco. Como señala J. M. Flambard (1981: 154-55), el ciudadano romano pertenecía a una serie de colectivos, tales como las tribus, el ordo, o la clase censitaria, con independencia de su voluntad; el status de ciudadano le incluía de forma automática en estos grupos. La pertenencia a un determinado collegium, por el contrario, dependía de la elección de cada individuo según sus propios intereses, exigiéndosele a cambio de la inclusión en el grupo y de los beneficios que ésta pudiera conllevar una serie de contraprestaciones en forma de pagos económicos o del desarrollo de determinadas actividades. La definición de aspectos más concretos, tales como la organización interna de los collegia, los intereses comunes de sus miembros y la influencia real que podían ejercer en el desarrollo de la política romana es lo que ha llevado a los estudiosos a una enconada polémica.

Los datos que nos ofrecen las fuentes sobre las distintas asociaciones de tipo voluntario en Roma se centran ante todo en la década que va del año 65 al 55 a.C., debido en gran medida a que los collegia se convirtieron en estas fechas en una cuestión de primer orden para la política romana1. Hasta el año 64 a.C., los collegia urbanos parecen existir en Roma sin ningún tipo de legislación específica que los regule. Sin embargo, ya en el 67 a.C., el tribuno de la plebe C. Manilio organizó una movilización de las masas urbanas para buscar el apoyo popular en sus

1 Para el establecimiento de esta cronología seguimos la reconstrucción de J. M. Flambard (1977: 117-20), con cuyas líneas generales estamos de acuerdo, pero algunas de cuyas reflexiones e interpretaciones sobre los datos analizados no compartimos. 
proyectos legislativos. Algunos autores han querido relacionar este acontecimiento y la fecha en que tuvo lugar con la celebración de los Compitalia, fiestas religiosas que incluían juegos y celebraciones urbanas, organizados tradicionalmente por los collegia (Flambard 1981: 162-63). Finalmente, en el año 64 a.C., un senatus consultum ordena la disolución de estos grupos y prohíbe la creación de nuevos collegia, una medida legislativa enmarcada dentro del clima de temor que precedió a la represión de Catilina y sus seguidores y de la cual nuestra principal fuente es un texto de Asconio ${ }^{2}$. En el año 61 a.C. hubo una tentiva fallida de violar este decreto del Senado por parte de algunos collegia, que trataron de celebrar los Compitalia. Con Publio Clodio recién nombrado tribuno de la plebe, los collegia consiguen celebrar sus fiestas de nuevo, bajo la presidencia de Sexto Cloelio, escriba y seguidor del tribuno. En esta misma línea de actuación, Clodio hace aprobar su lex de collegiis, que devolvía la legalidad a estas asociaciones y permitía la formación de nuevos collegia. En el 56 a.C. un nuevo senatus consultum trata de prohibir una vez más la existencia de estos grupos urbanos ${ }^{3}$, aunque la extensión y eficacia de esta medida ha sido muy debatida por la ambigüedad de los términos en los que ha llegado hasta nosotros. Al año siguiente, una lex Licinia completaba el decreto del Senado, pero también en esta ocasión desconocemos si la prohibición afectó a todos los collegia o únicamente a un tipo determinado.

Los intentos de dotar de contenido a este esquema cronológico han suscitado un gran número de interpretaciones acerca de las posibles formas de asociaciones urbanas existentes, su composición o la medida en que afectaron a cada una las disposiciones legales señaladas.

En los orígenes de esta discusión académica se encuentran los trabajos de Th. Mommsen (1843: 74-76), que, basándose en el estudio de una inscripción tardía de Fiesole ${ }^{4}$, crea el término collegia compitalicia, una expresión que, pese a no estar documentada en las fuentes antiguas, se consolidó como definitoria de todos o parte de los collegia romanos. Como vemos, este autor traza una relación directa entre los collegia y la celebración de los Compitalia, por lo que la supresión de los primeros habría ocasionado el fin de estas celebraciones. Mommsen hizo un intento de articular el concepto de collegia citado por Asconio con otras demarcaciones territoriales citadas en las fuentes, como montes, pagi y vici. Según su teoría el compitum estaría constituido por un número determinado de vici o barrios, que tendrían sus propios magistrados y que constituirían los collegia compitalicia, encargados de la celebración de los Compitalia. Para Mommsen, por tanto, la base de la formación de los collegia sería territorial, una interpretación que dejaría fuera a las asociaciones de tipo religioso y profesional documentadas en las fuentes.

Waltzing (1895-1900) realizó una demoledora crítica a las teorías de Mommsen, afirmando que sus hipótesis estaban basadas en presupuestos imaginarios sin apoyo alguno en las fuentes. La invención del término collegia compitalicia le

\footnotetext{
2 Asc. in Corn. 75c.

${ }^{3}$ Cic. ad Q.fr. 2.3.

4 CIL IX 1550.
} 
Publio Clodio y la lex de collegiis: una aproximación al fenómeno asociativo...

resulta a este autor totalmente gratuita, así como la definición de los collegia como la suma de varios vici. En su opinión toda esta reconstrucción únicamente existiría en la imaginación de Mommsen, y, desde luego, no correspondería al fenómeno asociativo en la época de Cicerón y Clodio. Aunque reconoce cierta importancia al factor territorial, para Waltzing la composición de los collegia seguiría pautas de tipo religioso y profesional. Con esta base como punto de partida, este autor ofrece una clasificación de los collegia según los intereses comunes de sus miembros y las actividades a las que éstos se dedicaran.

A lo largo del siglo XX los investigadores han tratado de conciliar ambas teorías acerca de la composición de los collegia, y aunque ha habido quien ha persistido en mantener las rígidas definiciones que dividían las asociaciones según sus orígenes o sus fines - territorial, profesional, religioso, funerario...-, la tendencia actual (Lintott 1967), a la cual nos adscribimos, es a considerar los collegia como un fenómeno complejo que dificilmente puede quedar encorsetado en las definiciones creadas ex nihilo por los historiadores modernos. Considerar que una asociación de tipo voluntario, en una sociedad como la romana, podía tener una sola faceta y un único objetivo constituye una simplificación excesiva que no responde a la realidad del mundo antiguo. En primer lugar, dudo de la existencia de algún tipo de asociación profesional que no estuviera relacionada con algún tipo de culto y de práctica religiosa compartida por sus miembros. Por otro lado, las asociaciones de tipo religioso podían perfectamente tener, más allá de las actividades propias del culto, una finalidad práctica, como la ayuda mutua entre los miembros en situaciones particulares tales como funerales $u$ otros momentos de necesidad. La separación, por tanto, entre collegia profesionales, religiosos, funerarios y otros tipos, constituye una recreación artificial resultado únicamente de una lectura forzada de las fuentes. Estos mismos argumentos pueden aplicarse para dudar de la existencia de collegia que respondieran exclusivamente al criterio territorial o a la residencia de sus miembros. La religión, el trabajo y el espacio en el que desarrollan los hombres sus actividades son realidades transversales que se cruzan constantemente en las sociedades antiguas y que nunca constituyen entidades separadas. Tratar de analizar la sociedad romana en base a una separación que sólo existe en el mundo industrial contemporáneo, e incluso en éste de manera cuestionable, sólo puede conducir a errores y falsas interpretaciones.

Una vez más debemos insistir en que estas asociaciones de tipo voluntario cumplían el papel de cubrir las necesidades de los habitantes de una comunidad que no quedaban satisfechas por las instituciones estatales o las redes familiares. Dejando de lado la institución del parentesco, de indudable importancia en el mundo romano, hay que tener en cuenta que las instituciones del Estado republicano dejaban, debido a su escaso desarrollo, un enorme campo de necesidades que el habitante de la ciudad debía llenar bien mediante la iniciativa privada, bien, en el caso de las clases bajas, recurriendo a redes voluntarias de solidaridad mutua. Es en este espacio donde los collegia urbanos tienen su razón de ser.

Sin embargo, no podemos caer en la tentación de idealizar los collegia más allá de los marcos de sociabilidad y solidaridad mutua que son. Aunque sean institu- 
ciones voluntarias y, en principio y durante la mayor parte de la República, ajenas al control y la legislación estatal, los collegia no dejaban de estar insertos en una realidad social muy concreta. En gran medida, estas asociaciones reproducen en pequeña escala las estructuras mentales de una sociedad compleja, y no están libres de sus prejuicios y convenciones. No podemos estar de acuerdo con F. Favory (1978-1979: 179) cuando afirma que los collegia eran espacios en los que los esclavos y libertos encontraban una estructura que disipaba las diferencias de status y las frustraciones que éstas conllevaban. Ni los esclavos dejaban de ser esclavos en el seno de estos grupos, ni los collegia constituían una sociedad paralela a la de las gentes aristocráticas. Esta idea la desarrolló Favory siguiendo el postulado de Waltzing, según el cual el funcionamiento de los collegia se basaba en estructuras democráticas en las que todas las decisiones se tomaban bien por los magistrados elegidos, bien en una asamblea general (Waltzing 1895-1900: 513-14).

La visión idealizada de estos dos autores podía darse únicamente en aquellos collegia que contaran exclusivamente entre sus miembros con individuos de un mismo grupo social, bien esclavos, bien libertos, bien individuos de condición libre. Resulta difícil de creer que un collegium que acogiera miembros de toda condición no contemplara en su normativa algún tipo de diferenciación entre los mismos. La noción de igualdad que el caso contrario habría requerido resulta totalmente ajena a la mentalidad romana.

La clave para estudiar esta cuestión nos la ofrecen los análisis de J. M. Flambard sobre un corpus epigráfico que recoge listas de magistrados de los collegia de varias ciudades de la Península Itálica (Flambard 1981: 157). Según sus conclusiones, los casos de collegia que contaban entre sus miembros únicamente con individuos de condición libre son totalmente minoritarios, mientras el resto están constituidos por asociaciones, o bien de composición mixta, de libertos y esclavos en su mayoría, o bien por individuos de condición u origen exclusivamente servil. Esto supone, en primer lugar, que debió de existir una cierta aversión por parte de los individuos libres a inscribirse en determinados collegia junto con esclavos o libertos. Por otro lado, las listas de magistrados parecen seguir un orden jerárquico bastante estricto en el que nunca un esclavo aparece en primer lugar por delante de individuos libres o libertos.

Aunque el corpus epigráfico utilizado por Flambard no corresponda estrictamente a la ciudad de Roma, podemos trasladar sin demasidos problemas sus conclusiones para aplicarlos a los collegia de la Urbe. Observamos, por tanto, que la situación real documentada en las fuentes se encuentra muy lejos del ideal igualitario propuesto por Favory y Waltzing. Los collegia reproducían en su composición y estructura los prejuicios de la sociedad, y dichos prejuicios quedaban plasmados en sus normativas y estatutos. Aunque la falta de datos en las fuentes nos impida afirmarlo con mayor detalle, sin duda existieron diferencias entre los derechos y las obligaciones de las que disfrutaban los individuos de diferente condición en un mismo collegium.

La cuestión de la mayor o menor influencia que los collegia pudieran ejercer en la política romana ha generado también opiniones encontradas. El hecho de que es- 
Publio Clodio y la lex de collegiis: una aproximación al fenómeno asociativo...

tas asociaciones desarrollaran su actividad sin estar sujetas a una legislación específica durante varios siglos supone que su influencia en los resultados electorales y en la votación de proyectos legislativos de la Urbe debió de ser relativamente escasa hasta, al menos, los inicios de la crisis de la República. Estas estructuras urbanas poco peso podían tener en los comicios, tanto por centurias como por tribus: en los primeros la condición mayoritaria de proletarii de sus miembros les dejaba fuera de la unidad de voto; en los comicios por tribus su presencia, al estar sus socios en su mayoría encuadrados en las tribus urbanas, contaba relativamente poco en la totalidad de las 35 existentes en época ciceroniana. Pese a esto, los políticos que buscaban ser elegidos para alguna magistratura no olvidaban en sus campañas a los líderes de los principales collegia, ya que, ganándose su favor, podían contar con el apoyo del resto de los miembros ${ }^{5}$. Aunque ninguna candidatura podía asegurar su éxito en los comicios contando sólo con el favor de los collegia urbanos, el apoyo de estos grupos aseguraba al político en cuestión una notable medida de presión con la que podía llegar a imponer sus proyectos. ¿En qué momento empezaron a ser tenidas en cuenta por los aristócratas estas estructuras urbanas de asociación?

La tendencia creciente a buscar el apoyo de las masas urbanas por parte de los candidatos y magistrados es posiblemente una de las características que definen con mayor exactitud la vida política de la República romana después del tribunado de Tiberio Graco. Los collegia no permanecieron ajenos a este fenómeno que concedía un protagonismo cada vez mayor a la plebe urbana como elemento de poder, más allá de su capacidad real de influencia en los comicios como unidad de voto. Sin embargo, el poder de la plebe urbana se manifestaba con demasiada facilidad en forma de episodios de violencia, bien incontrolada o bien dirigida por algún individuo. Fue esta situación lo que llevó al Senado a cobrar conciencia de la necesidad de regular la actividad de estos grupos y, en última instancia, a prohibir la actividad de los collegia mediante un senatus consultum en el año 64 a.C.

Pero, sin duda, fue Publio Clodio Pulcher el aristócrata que comprendió con mayor claridad este fenómeno que convertía, con independencia de las medidas represivas del Senado, a la plebe urbana en una pieza fundamental a tener en cuenta para lograr la supremacía política en una República cuyas instituciones tradicionales iban quedando cada vez más desfasadas ante las nuevas necesidades de una sociedad cambiante.

\section{LEX CLODIA DE COLLEGIIS RESTITUENDIS NOVISQUE INSTITUENDIS}

Hemos analizado cómo la creciente influencia de los collegia en la vida política de la Urbe y en los episodios violentos que en ella se produjeron a mediados del siglo I a.C. Ilevó al Senado a emitir un decreto que obligaba a su disolución y prohibía la formación de nuevas asociaciones. La ley de Clodio iba dirigida de una ma-

5 Comm. Pet. 30 . 
nera directa contra este sentus consultum, pues no sólo devolvía a la legalidad a los collegia ya existentes sino que permitía la creación de nuevas asociaciones. Según W. J. Tatum, autor de la biografía moderna de Clodio más completa y rigurosa (Tatum 1999: 118), fue precisamente a la formación de estos nuevos collegia a lo que el tribuno dedicó más energías durante su tribunado. La creación de estas nuevas asociaciones estarían detrás de lo que Cicerón describe como reclutamientos de esclavos por barrios ${ }^{6}$. Siguiendo la información ofrecida por el propio Arpinate, según la cual Clodio habría utilizado el tribunal Aurelio para llevar a cabo el reclutamiento de sus bandas, Tatum interpreta que lo que en realidad el tribuno habría hecho en este lugar sería organizar las listas de los nuevos collegia. Este autor no quita sin embargo toda la credibilidad al testimonio de Cicerón, pues considera real la afirmación del Arpinate acerca de la presencia mayoritaria de esclavos en los nuevos collegia, así como en las bandas de Clodio. En sus filas se habrían integrado todos aquellos habitantes de la Urbe que, con anterioridad a la lex Clodia, habrían sido incapaces de entrar en otros collegia debido a su extrema pobreza y a la imposibilidad de sufragar los gastos que la pertenencia a un colectivo de este tipo supondría. Dentro de estos grupos la población servil constituiría, siempre según Tatum, una mayoría. Los nuevos collegia de Clodio ofrecerían a estos individuos pertenecientes a las clases más depauperadas la posibilidad de integrarse en un grupo creado a la medida de sus posibilidades económicas.

Estemos de acuerdo o no con las interpretaciones de Tatum, lo cierto es que la lex de collegiis consiguió convertir a Clodio en el nuevo campeón de la plebe. La lex Clodia frumentaria, que aseguraba a cada ciudadano una ración mensual gratuita de trigo, contribuyó a aumentar la fama del tribuno entre las clases bajas de la Urbe. Mediante un mismo paquete de medidas legislativas, Publio Clodio había devuelto al pueblo la posibilidad de revivir sus marcos tradicionales de asociación, prohibidos por el Senado años atrás, y, al mismo tiempo, había solucionado, en apariencia, la siempre problemática cuestión del aprovisionamiento de trigo entre los habitantes de la ciudad. La plebe, a cambio de estas medidas, aprobó con entusiasmo todos los proyectos propuestos por el tribuno a lo largo de su mandato, incluyendo la ley que condenaba al exilio a Cicerón. Con el control de la plebe en sus manos, Clodio se convirtió en el político más fuerte de la ciudad, al menos mientras supo conservar su influencia sobre las masas. El tribuno se convirtió en el patrón político de, al menos, los nuevos collegia creados al amparo de su ley y, podemos suponer, de muchos de los ya existentes a los que él había devuelto a la legalidad. Naturalmente, Clodio no ejercía el control de estas asociaciones de una manera directa, pero podemos seguir a Cicerón una vez más y encontrar como mediadores entre el aristócrata y los magistri de los collegia a algunos de sus hombres más fieles, como Sexto Cloelio o C. Clodio.

Como acertadamente apunta Lintott (1968: 77-83), Publio Clodio fue el primer magistrado romano que incluyó entre los objetivos de su política la creación de un sistema mediante el cual ejercer el control sobre la plebe urbana. Con lo que no

6 Cic. Dom. 129. 
Publio Clodio y la lex de collegiis: una aproximación al fenómeno asociativo...

podemos estar de acuerdo es con la idea de que toda la política de Clodio se articulara en base a conseguir esta influencia sobre las masas y teniendo esta idea como objetivo último: el control de la plebe fue un medio, pero no el fin perseguido por el tribuno. En mi opinión el objetivo de Clodio fue, al menos desde su tribunado, arrebatar al Senado una serie de prerrogativas para ponerlas en manos, bien de las asambleas y comicios, bien de determinados magistrados. Tanto el contar con el favor de la plebe urbana como el utilizar sus estructuras asociativas como medio de presión violenta, le sirvieron al tribuno para llevar a cabo sus objetivos, al menos parcialmente.

En primer lugar, la lex de collegiis aquí analizada, aunque puede ser interpretada como el intento más claro por parte del tribuno de ganar popularidad ante la plebe, y sin duda esta fue una de sus consecuencias, constituyó también un ataque directo a la política autoritaria llevada a cabo por el Senado a lo largo de los años 60. La decisión unilateral tomada por la Curia en el año 64 a.C. de prohibir los collegia urbanos fue contestada por el tribuno del 58 a.C. mediante una ley, presentada por uno de los representantes del pueblo y aprobada por los comicios por tribus. La lex de collegiis supone, por tanto, un desafío directo a la autoridad del Senado y una demostración por parte de Clodio de que el sistema político y legislativo romano podía funcionar sin la intervención de la Curia.

Por otro lado, no es únicamente esta ley la que puede ser interpretada en este sentido: el resto de la legislación clodiana encaja a la perfección dentro del objetivo de restar poder a la autoridad del Senado. Durante su ejercicio del tribunado Clodio asumió la defensa de los derechos del pueblo frente a la arbitrariedad de la aristocracia senatorial; la lex Clodia de capite civis Romani, aunque se haya querido interpretar demasiado a menudo como la venganza personal de Publio Clodio sobre Cicerón por su testimonio durante el escándalo de la Bona Dea (Lintott 1967), es en realidad una medida legal de carácter amplio que impedía que cualquier ciudadano fuese ejecutado sin un juicio previo, incluyendo situaciones excepcionales como las previstas por el senatus consultum ultimum. Mediante esta ley, el Senado quedaba privado del principal mecanismo de represión con el que había contado desde, al menos, la muerte de Cayo Graco, mientras el derecho a la provocatio de todos los ciudadanos romanos quedaba asegurado.

Publio Clodio llegó a arrebatar al Senado incluso el poder de decisión sobre determinados aspectos de la política exterior, una prerrogativa que tradicionalmente había estado únicamente en manos del ordo senatorial. Esto queda plasmado en su lex Clodia de imperio Catonis, mediante la cual se anexionaba Chipre a los dominios de Roma y se intervenía en la cuestión de los exiliados en Bizancio.

La lex Clodia de collegiis restituendis novique instituendis, por tanto, proporcionó al tribuno una base de apoyo popular desde la cual pudo ejercer con comodidad su magistratura, pero esto no quiere decir que el único objetivo de Clodio fuese el control de la plebe. Esta ley, como todos los proyectos legislativos emprendidos por el tribuno, debe ser interpretada como un paso más en la confrontación entre aquellos aristócratas que deseaban que la base de la política romana permaneciese en el Senado y los políticos que, por otro lado, veían la ne- 
cesidad de una serie de reformas que concediesen mayores poderes a los magistrados y las asambleas.

El éxito de Clodio en este sentido fue sólo relativo. Si bien durante su tribunado logró convertirse en el hombre fuerte de la política romana y arrebatar al Senado gran parte de su autoridad, los adversarios de Clodio no tardaron en copiar su estrategia de utilizar la violencia urbana para imponer sus propuestas en los comicios y asambleas, así como anular mediante la fuerza las de sus oponentes. Los enfrentamientos entre bandas ocasionaron un colapso del sistema político republicano, que sólo pudo ser contrarrestado mediante la concesión de poderes extraordinarios a Pompeyo.

Aunque años después de su tribunado el poder y la influencia de Publio Clodio habían disminuido notablemente debido a los cambios de alianzas entre la aristocracia romana, éste siempre mantuvo su carácter de político cercano al pueblo, un hecho que quedó plasmado en los violentos altercados que tuvieron lugar en la ciudad tras su muerte, a manos de los hombres de Milón.

\section{BIBLIOGRAFÍA}

FAVORY, F. (1978-79), «Clodius et le péril servile: fonction du thème servile dans le discours polémique cicéronien», Index 8, 173-205.

FLAMBARD, J. M. (1977), «Clodius, les collèges, la plèbe et les esclaves», MEFRA 89.1, 115-56.

- (1981), "Collegia compitalicia: phénomène associatif, cadres territoriaux et cadres civiques dans le monde romaine à l'époque républicaine», Ktema 6, 143-166.

LINTOTT, A. W. (1967), «P. Clodius Pulcher, Felix Catilina?», G\&R 14, 157-69.

- (1968), Violence in Republican Rome, Oxford.

MOMMSEN, T. (1843): De collegiis et sodaliciis Romanorum, Kiel.

PINA POLO, F. (1991), “Cicerón contra Clodio: el lenguaje de la invectiva», Gerión 9, 131-50.

TATUM, W. J. (1999), The Patrician Tribune, London.

WALTZING, J. P. (1895-1900), Étude Historique sur les Corporations Profesionnelles chez les Romains depuis les Origins jusqu'à la Chute del Empire d'Occident, 4 vols., Lovaina. 